\title{
Prevalence of dating violence among teenagers in Mississippi
}

\author{
Temiloluwa Sokoya*, Nwanne Onumah ${ }^{* *}$, Praise Ebimaye Tangbe $_{* * *}^{*}$, Border-ere Fiemotonghan ${ }^{* * *}$
}

*Department of Behavioral and Environmental Health, Jackson State University
**Department of Epidemiology and Biostatistics, Jackson State University
***Department of Public Policy and Administration, Jackson State University

DOI: 10.29322/IJSRP.11.09.2021.p11721

http://dx.doi.org/10.29322/IJSRP.11.09.2021.p11721

\begin{abstract}
Background: Dating violence is prevalent among high school teenagers in Mississippi and is currently a public health issue that needs intervention.

Aims and objectives: This study aims to assess the prevalence of dating violence among high school teenagers in Mississippi and to determine the association of race, sex, gender, and grade level in dating violence experiences

Methods: This study analyzed data from the 2019 Mississippi Youth Risk Behavior (YRBS), a cross-sectional school-based survey that collected data from students in 9 th grade to $12^{\text {th }}$ grade in private and public schools. The data assessed the variations in demographic subdivision, thus observing any change in prevalence.

Results: Our results indicate that female participants had higher rates of sexual violence (females:14.8\%, males:(7.6\%), sexual dating violence (females:10.3\%, males:2.3\%) and physical violence (females:10.9\%, males:7.2\%) than their male counterparts. Students aged 15 and younger are more likely to be victims of sexual violence, sexual dating violence, and physical violence than teenagers 16 or older. White females $(7.8 \%)$ had higher rates of sexual dating violence when compared to blacks $(5.0 \%)$. Also, Blacks are more likely to be victims of physical dating violence while Whites are more likely to be victims of sexual dating violence.

Conclusions: Intimate partner violence affects teenagers of all ages, gender, and race. However, due to the high prevalence rate among women, they are particularly vulnerable - teenagers 15 and younger and females experience a higher rate of physical, sexual dating violence and sexual violence. Thus, there is an urgent need for violence awareness programs in high schools to help teenagers identify dating violence and seek help.
\end{abstract}

Index Terms- Teenagers, Intimate partner violence, dating violence, Physical violence, sexual violence

\section{INTRODUCTION}

$\mathrm{T}$ he adolescent period is a period when teenagers start puberty and sometimes start to experience their first dating relationships. So many teenagers are vulnerable and get into different forms of unhealthy and violent relationships at this stage. Teen dating violence (TDV) or intimate partner violence (IPV) affects millions of teenagers in the United States [4] and a lot of times, they do not speak up about it because of stigma [20] and how it has affected their sense of self-efficacy [11]. Aside from stigma, some of these teenagers do not have adequate knowledge about dating violence and sometimes see it as a norm, especially those that had adverse childhood experiences $[10,15]$. Teens are used to teasing one another and calling one another names and sometimes cannot identify when it has become an abuse [4].

Teen dating violence can be perpetrated in person (physical, sexual, psychological and or stalking) or online (e.g., repeated texting, posting of partner's nude or sexual pictures online without their permission) [4]. According to Centers for Disease Control and Prevention [4], 1 in 9 high school females in the United States have experienced sexual dating violence and 1 in 36 male high school students have experienced sexual dating violence. Also, 1 in 15 males in high school have experienced physical dating violence while 1 in 11 females in high school have experienced physical dating violence [4]. This issue of violence among teenagers needs to be addressed as it can lead to negative health outcomes like depression, anxiety, drug use and suicide [4,]. The effect of dating violence is not just immediate but also long term. According to Exner-Cortens [9], teenagers who are victimized are more likely to experience intimate partner violence 12 years after.

\section{Factors Influencing Teen Dating Violence}

One major factor that influences the perpetration and victimization of dating violence or intimate partner violence is adverse childhood experiences. A lot of times, children model the behavior of their parents [10]. In a cross-sectional study carried out on college students, it was reported that a male child is more likely to perpetrate IPV and a female child is more likely to be a victim when they witness an adult male in their home perpetrating intimate partner violence [10]. Also, when a male or female adolescent see a female adult perpetrating IPV, it increases their risk of being perpetrators or victims [10]. This is also similar to a report by CDC [5] that states that victimization of IPV is mainly influenced by adverse childhood experiences.

There has also been a link between marijuana, alcohol consumption, substance abuse [2,17] and intimate partner violence. Consistent use of marijuana is associated with being a perpetrator of intimate partner violence and when it is used throughout adolescent life, it increases the probability of being both a perpetrator and victim of intimate partner violence when 
the person becomes a young adult [18]. Moore [16] reported in their study on college students, that students are two to three times more likely to perpetrate physical and psychological aggression on days that they drink than on days that they did not. Huffhines [12] also reported that teenagers are more likely to start smoking before the age of 13 and are more likely to smoke more than ten cigarettes per day when they experience teen dating violence.

Knowledge about intimate partner violence increases the chance of a teenager intervening as a bystander of violence most especially sexual assault because they are well informed on what to do and how to protect the victim [13].

\section{Signs of Exposure to Dating Violence}

Teenagers that experience or have been exposed to dating violence are more likely to exhibit some of these behaviors: withdrawal, poor sleep, depression, anxiety, suicidal thoughts, aggressive behaviors to peers, substance abuse, early onset- sexual activity, have multiple dating and sexual partners, exhibit rude and anomaly behaviors in school $[6,22]$ and at home $[8,15,19]$. The overall academic performance of the teen drops [14] and there is irregular school and class attendance with the sole intention of spending time with their partner [6].

In the state of Mississippi, there are cases of violence being reported by teenagers, but no study has been carried out on the prevalence among teenagers. Using the Youth Risk Behavior Surveillance System (YRBSS), this study aims to examine the prevalence of dating violence among teenagers in the state of Mississippi by gender, grade, and race. This will help to increase knowledge about teen dating violence victimization and perpetration in Mississippi as well as help social workers to create intervention programs for teenagers who are victims and perpetrators of dating violence and programs for their parents or caregivers.

\section{METHOD}

Data from the 2019 Mississippi High School Youth Risk Behavior Survey (YRBSS) was used for the analyses. The YRBSS is a cross-sectional school-based survey from which data is collected from public and private school students in grades $9^{\text {th }}$ to $12^{\text {th }}$ grade in Mississippi, United States. The data assessed the variations in demographic subdivision, thus observing any change in prevalence. The sample size was 1,697. Demographic characteristics of the participants included race/ethnicity (White, Black, Hispanic, and Other), grade level (9th, 10th, 11th, and 12 th), gender, age (15 or younger, 16 or 17,18 or older). The Intimate partner violence was assessed by asking the following questions: [1] "During the past 12 months, how many times did anyone force you to do sexual things that you did not want to do?", [2] "During the past 12 months, how many times did someone you were dating or going out with force you to do sexual things that you did not want to do?" [3] "During the past 12 months, how many times did someone you were dating or going out with physically hurt you on purpose?" The response options were dichotomized into categories: $\geq 1$ time versus 0 times. The estimated prevalence of dating violence among participants were adjusted based on their age, race, gender, and grade reference from the CDC growth chart. The differences in the groups were examined by using the frequency distribution to determine the percentage differences.

\section{RESULTS}

Table 1. Shows the percentage of students who experienced sexual violence by anyone. $11.8 \%$ were 15 or younger, $11.4 \%$ were 16 or 17 years and $8.8 \%$ were 18 or older. Female participants (14.8\%) experienced higher rates of sexual violence than male participants (7.6\%). The participants who identified as being Hispanic/Latino (20.9\%) experienced higher rates of sexual violence when compared to black participants $(10.2 \%)$ and white participants (11.2\%). White females (17.5\%) experienced higher rates of sexual violence than the black females $(12.1 \%)$. Females who were in $10^{\text {th }}$ grade $(16.4 \%)$ experienced higher rates when compared to females in $9^{\text {th }}(15.8 \%), 11^{\text {th }}(12.5 \%)$ and $12^{\text {th }}$ grade $(14.2 \%)$.

Table 2. Percentage of students who experienced sexual dating violence are shown. Female participants $(10.3 \%)$ experienced higher rates of sexual dating violence experience than male participants $(2.3 \%) .7 .1 \%$ of the participants who were 15 years or younger and $6.3 \%$ of the participants were between 16 or 17 experienced sexual dating violence. Female participants in $12^{\text {th }}$ grade $(13.2 \%)$ experienced higher rates of sexual dating violence experience when compared to those in $9^{\text {th }}(8.2 \%), 10^{\text {th }}(9.5 \%)$ and $11^{\text {th }}(10.0 \%)$ grade. White participants $(7.8 \%)$ experienced higher rates of sexual dating violence when compared to blacks (5.0\%) which is relatively similar to the findings for the female white participants (14.1\%) when compared to black females (6.9\%).

Table 3. Demonstrates the percentage of students who experienced physical dating violence. Female participants who were 15 or younger $(10.0 \%)$ experienced higher physical dating violence when compared to female participants who were 16 or 17 years old $(9.9 \%)$. Participants in $12^{\text {th }}$ grade $(14.7 \%)$ had the highest rates of physical dating violence experiences when compared to those in $9^{\text {th }}(7.9 \%), 10^{\text {th }}$ grade $(9.5 \%)$ and $11^{\text {th }}$ grade $(6.0 \%)$ respectively. Participants who identified as being black (12.9\%) experienced higher rates of physical dating violence when compared to white participants $(5.4 \%)$. Female black participants $(16.0 \%)$ experienced higher rates than female white participants $(5.5 \%)$. Also, black males $(9.1 \%)$ experienced higher rates of physical dating violence when compared to white males (5.4\%). 
Table 1. Percentage of students who experienced sexual violence by anyone*

Total

Percentage (\%)

Total

(n)

11.3
Male (\%)

Female

Percentage Total(n)

(\%)

$\begin{array}{llll}1697 & 7.6 & 838 & 14.8\end{array}$

14.8

847

Total

Race

Black

White

Hispanic/Latino

Grade
$9^{\text {th }}$
$10^{\text {th }}$
$11^{\text {th }}$
$12^{\text {th }}$

Age
10.2

11.2

20.9

11.6

11.3

9.2

12.6

11.8

11.4

8.8
557

420

329

378
661

703

144

7.8
5.9
N/A

7.8

N/A

308
368
77

12.1

17.5

N/A

351

332

64

$\begin{array}{lcccccc}15 \text { or younger } & 11.8 & 809 & 7.8 & 391 & 15.8 & 412 \\ 16 \text { or 17 } & 11.4 & 759 & 7.6 & 379 & 15.0 & 376 \\ 18 \text { or older } & 8.8 & 126 & \text { N/A } & 67 & \text { N/A } & 58 \\ & & & \\ \text { Abbreviations: N/A: Not Available. Source: Youth Risk Behavioral Surveillance System (YRBSS), 2019. } \\ \text { *Being forced by anyone to do sexual things [counting such things as kissing, touching, or being physically forced to have sexual intercourse] } \\ \text { that they did not want to, one or more times during the 12 months before the survey. }\end{array}$

\section{DISCUSSION}

The 2019 Youth Risk Behavioral Surveillance System data was used to examine the prevalence of dating violence among high school students living in Mississippi. Findings from this study report the experience of dating violence by age, sex, grade, and race/ethnicity among high school students in Mississippi. Comparing the total rate of sexual violence perpetrated by anyone $(11.3 \%)$ to the total rate of dating sexual violence in a dating relationship (6.6\%), over 60 percent of sexual violence among high school students in Mississippi are perpetrated by a dating/intimate partner. Comparing the findings to the overall YRBSS 2019 data in the United States, although high school students in Mississippi experienced lower rate of sexual dating violence $(6.6 \%)$ when compared to the national rate of $8.2 \%$, however, they experience a higher rate of physical dating violence $(9.4 \%)$ compared to the U.S rate of $8.2 \%$ [3].
Examining the prevalence of physical and sexual dating violence and their demographic characteristics, we found out that there is a high gender disparity between male and female. This implies that high-school female is at high risk of sexual or physical violence when compared to a male of the same age group. This result is similar to the study by Basile [3] and Earnest [7] that the prevalence of intimate partner violence among teenagers is higher among females than males. The result from this study also points out the difference among races when it comes to dating violence. In this study, white students experienced higher sexual dating violence when compared to black students. On the other hand, black students experienced higher rate of physical dating violence when compared to their white counterparts. This is consistent with past findings that African American women are more likely to be involved in teen dating violence than Caucasians [1]. 
Table 2. Percentage of students who experienced sexual dating violence**

Total

Percentage $(\%)$

5.0

7.8

White

Hispanic/Latino

N/A

$12^{\text {th }}$

Age

15 or younger
16 or 17
18 or older

7.1
6.3
N/A

Male

$\begin{array}{ll}\text { Total } & \text { perce } \\ (\mathrm{n}) & (\%) \\ 1125 & 2.3\end{array}$

$\%)$

ercentage

1125

2.3

$\begin{array}{ll}449 & 2.7 \\ 448 & 1.9 \\ 80 & \text { N/A }\end{array}$

$\begin{array}{ll}449 & 2.7 \\ 448 & 1.9 \\ 80 & \text { N/A }\end{array}$

$\begin{array}{ll}449 & 2.7 \\ 448 & 1.9 \\ 80 & \text { N/A }\end{array}$

\section{3}

5.7

5.9

9.4

2.6
1.8
1.1
4.0

2.6

$\mathrm{N} / \mathrm{A}$

487
544
93

Female

$\begin{array}{lll}\begin{array}{l}\text { Total } \\ (\mathrm{n})\end{array} & \begin{array}{l}\text { Percentage } \\ (\%)\end{array} & \text { Total(n) } \\ 545 & 10.3 & 577\end{array}$

$\begin{array}{lll}204 & 6.9 & 351 \\ 247 & 14.1 & 241 \\ 46 & \text { N/A } & 32\end{array}$

351

32

\footnotetext{
Abbreviations: N/A: Not Available. Source: Youth Risk Behavioral Surveillance System (YRBSS), 2019.

**being forced by someone they were dating or going out with to do sexual things [counting such things as kissing, touching, or being physically forced to have sexual intercourse] that they did not want to, one or more times during the 12 months before the survey, among students who dated or went out with someone during the 12 months before the survey.
}

However, it is contrary to the study carried out by Temple [21] among high school students in Southeast Texas which reported that there is no difference in dating violence rate among African Americans, Whites and Caucasians. Also in our study, there is a high rate of sexual and physical dating violence among $12^{\text {th }}$ graders compared to the $9^{\text {th }}, 10^{\text {th }}$, and $11^{\text {th }}$ graders. Furthermore, our findings denote that students ages 15 or younger experienced higher prevalence rate Despite the relevance of this study, there are several limitations in our analysis. Firstly, the study being a secondary data is limited to specific information that we do not have control over such as the data collection process. The study captured sexual and physical violence and no other types of violence like psychological and verbal violence. Also, the YRBSS data only applies to teenagers who attend school and therefore might not be a representative of all the teenagers in Mississippi; those teenagers who dropped out of school and those that did not enroll in school were excluded. Lastly, the fact that YRBSS data is based on cross-sectional survey design, it is limited to providing an indication of association, which prevents deduction about causality. Regardless of the limitations of this research, this study findings adequately report the prevalence of sexual and physical dating violence among high school students in Mississippi. Our findings will serve as an important tool for evidence-based interventions for preventing dating violence among high school students. 
Table 3. Percentage of students who experienced physical dating violence ***

\begin{tabular}{lllllll}
\multicolumn{2}{c}{ Total } & \multicolumn{2}{c}{ Male } & \multicolumn{2}{c}{ Female } \\
& Percentage $(\%)$ & $\begin{array}{l}\text { Total } \\
(\mathrm{n})\end{array}$ & $\begin{array}{l}\text { Percentage } \\
(\%)\end{array}$ & $\begin{array}{l}\text { Total } \\
(\mathrm{n})\end{array}$ & $\begin{array}{l}\text { Percentage } \\
(\%)\end{array}$ & Total(n) \\
Total & 9.4 & 1,166 & 7.2 & 558 & 10.9 & 602 \\
& & & & & & \\
Race & & & & & & \\
Black & 12.9 & 472 & 9.1 & 211 & 16.0 & 261 \\
White & 5.4 & 500 & 5.4 & 250 & 5.5 & 250 \\
Hispanic/Latino & N/A & 84 & N/A & 47 & N/A & 32 \\
& & & & & & \\
Grade & 7.9 & 348 & 7.0 & 182 & 8.9 & 166 \\
$9^{\text {th }}$ & 9.5 & 299 & 8.2 & 151 & 10.1 & 146 \\
$10^{\text {th }}$ & 6.0 & 235 & 4.8 & 103 & 6.6 & 131 \\
$11^{\text {th }}$ & 14.7 & 277 & 9.1 & 118 & 18.0 & 156 \\
$12^{\text {th }}$ & & & & & & \\
Age & & & & & & \\
15 or younger & 9.1 & 513 & 6.9 & 245 & 10.0 & 264 \\
16 or 17 & 8.8 & 558 & 7.4 & 269 & 9.9 & 288 \\
18 or older & N/A & 94 & N/A & 44 & N/A & 49
\end{tabular}

\footnotetext{
Abbreviations: N/A: Not Available. Source: Youth Risk Behavioral Surveillance System (YRBSS), 2019.

***being physically hurt on purpose by someone they were dating or going out with [counting such things as being hit, slammed into something, or injured with an object or weapon] one or more times during the 12 months before the survey, among students who dated or went out with someone during the 12 months before the survey.
}

\section{CONCLUSION}

Dating violence is prevalent among especially high school students in Mississippi, however, it is preventable. There is a need for violence awareness programs to be carried out by nongovernmental organizations, governmental organizations, and different coalitions against domestic violence to increase the knowledge of teenagers on dating violence. This will help teenagers to identify violent behaviors in their dating partner and/or friends and in themselves. Schools and social workers should organize classes for parents on parenting and how to be good role models for their children and encourage them to take the classes. More research should be carried out on the impact and severity of teen dating violence based on gender and race as these people may experience violence differently.

\section{REFERENCES}

[1] Ahonen, L., \& Loeber, R. (2016). Dating violence in teenage girls: parental emotion regulation and racial differences. Criminal Behaviour And Mental Health, 26(4), 240-250. doi: 10.1002/cbm.2011.

[2] Baker, C. K. (2016). Dating violence and substance use: Exploring the context of adolescent relationships. Journal of Interpersonal Violence, 31(5), 900-919. doi:10.1177/0886260514556768.
[3] Basile, K. C., Clayton, H. B., DeGue, S., Gilford, J. W., Vagi, K. J., Suarez, N. A., ... \& Lowry, R. (2020). Interpersonal violence victimization among high school students - Youth risk behavior survey, United States, 2019. MMWR supplements, 69(1), 28.

[4] Centers for Disease Control and Prevention (2020, March 9). Preventing teen dating violence. https://www.cdc.gov/injury/features/datingviolence/index.html

[5] Centers for Disease Control and Prevention (2021, March 5). Sexual violence in youth. https://www.cdc.gov/violenceprevention/pdf/2012FindingsonSVinYouth$\underline{508 . p d f}$

[6] Chronister, K. M., Marsiglio, M. C., Linville, D., \& Lantrip, K. R. (2014) The influence of dating violence on adolescent girls' educational experiences. The Counseling Psychologist, 42(3), 374-405. doi: 10.1177/0011000012470569.

[7] Earnest, A. A., \& Brady, S. S. (2016). Dating violence victimization among high school students in Minnesota: Associations with family violence, unsafe schools, and resources for support. Journal of interpersonal violence, 31(3), 383-406.

[8] Edwards, K. M., \& Neal, A. M. (2017). School and community characteristics related to dating violence victimization among high school youth. Psychology of Violence, 7(2), 203-212. doi: 10.1037/vio0000065.

[9] Exner-Cortens, D., Eckenrode, J., Bunge, J., \& Rothman, E. (2017) Revictimization after adolescent dating violence in a matched, national sample of youth. Journal of Adolescent Health, 60(2), 176-183.

[10] Forke, C. M., Myers, R. K., Fein, J. A., Catallozzi, M., Localio, A. R., Wiebe, D. J., \& Grisso, J. A. (2018). Witnessing intimate partner violence as a child: How boys and girls model their parents' behaviors in adolescence. Child Abuse \& Neglect, 84, 241-252. 
[11] Hébert, M., van, C., Lavoie, F., Blais, M., \& Guerrier, M. (2014). Understanding the hesitancy to disclose teen dating violence: Correlates of self-efficacy to deal with teen dating violence. Temida, 17(4), 43-64. doi: 10.2298/tem1404043h.

[12] Huffhines, L., Zale, E., Thamotharan, S., Sferra, M., Lange, K., Ditre, J., \& Fields, S. (2014). Intimate Partner Violence, Sexual Abuse, and Cigarette Smoking Risk in Adolescents. Journal of Child \& Adolescent Trauma, 7(3), 175-183. doi: 10.1007/s40653-014-0024-x.

[13] Kimberly, C., \& Hardman, A. M. (2019). Mississippi college students' attitudes, willingness to intervene and legal knowledge toward sexual assault. Sex Education, 19(1), 68-83

[14] Martz, D. M., Jameson, J. P., \& Page, A. D. (2016). Psychological health and academic success in rural Appalachian adolescents exposed to physical and sexual interpersonal violence. American Journal of Orthopsychiatry, 86(5), 594-601. doi: 10.1037/ort0000174.

[15] Mississippi State Department of Health (n.d.). Teen Dating Violence Prevention. https://msdh.ms.gov/msdhsite/ static/44,0,388,784.html

[16] Moore, T., Elkins, S., McNulty, J., Kivisto, A., \& Handsel, V. (2011). Alcohol use and intimate partner violence perpetration among college students: assessing the temporal association using electronic diary technology. Psychology of Violence, 1(4), 315-328. doi:10.1037/a0025077.

[17] Parker, E. M., \& Bradshaw, C. P. (2015). Teen dating violence victimization and patterns of substance use among high school students. Journal of Adolescent Health, 57(4), 441-447. doi:10.1016/j.jadohealth.2015.06.013.

[18] Reingle, J. M., Staras, S. A., Jennings, W. G., Branchini, J., \& MaldonadoMolina, M. M. (2012). The relationship between marijuana use and intimate partner violence in a nationally representative, longitudinal sample. Journal of interpersonal violence, 27(8), 1562-1578.

[19] Rome, E.S., Miller, E. (2020). Intimate partner violence in the adolescent. Bibliotheque Univ Paris V, 41, 73-80.
http://pgnrc.sbmu.ac.ir/uploads/Intimate Partner Violence in the Adolesc ent.pdf

[20] Sitkans Against Family Violence (n.d.). Teen dating violence. https://www.safv.org/teen-dating-violence.

[21] Temple, J., \& Freeman, D. (2010). Dating Violence and Substance Use Among Ethnically Diverse Adolescents. Journal of Interpersonal Violence, 26(4), 701-718. doi: 10.1177/0886260510365858.

[22] Zabenko, O., Austic, E., Conroy, D. A., Ehrlich, P., Singh, V., Epstein-Ngo, Q., \& ... Walton, M. A. (2016). Substance use as a risk factor for sleep problems among adolescents presenting to the emergency department. Journal of Addiction Medicine, 10(5), 331-338. doi:10.1097/ADM.0000000000000243ไ.

\section{AUTHORS}

First Author - Temiloluwa Sokoya, MPH, Jackson State University, ogundeyitemiloluwa@gmail.com

Second Author - Nwanne Onumah, MBBS, Jackson State

University, MS, USA, nwanne01@yahoo.com

Third Author - Praise Ebimaye Tangbe, MPH, Jackson State

University, praise.tangbe@gmail.com

Fourth Author - Border-ere Fiemotonghan, MA, Jackson

State University, excelizzy@gmail.com

Correspondence Author - Temiloluwa Sokoya, MPH, Jackson

State University, ogundeyitemiloluwa@gmail.com,

J00914167@students.jsums.edu 